\title{
Abnormalities of chromosome 18 in a girl with mental retardation and autistic disorder
}

\author{
M. GHAZIUDDIN, S. SHELDON, L. Y. TSAI AND N. ALESSI \\ Departments of Child Psychiatry and Pathology, University of Michigan, Ann \\ Arbor, Michigan, USA
}

\begin{abstract}
Structural autosome defects have rarely been described in autism. In this report, the authors describe the association of autism and mental retardation in a girl with mosaicism for a duplication of the long arm of chromosome 18 and a deletion of the short arm of chromosome 18.
\end{abstract}

\section{INTRODUCTION}

Association of autism has been described with a number of chromosome abnormalities, especially of sex chromosomes. Few reports have described the association of autism with autosome abnormalities. Wakabayashi (1979) reported a case of autism with Down's syndrome, while Turner \& Jennings (1961) described the occurrence of chromosome 22 abnormalities in autistic persons. Meriner et al. (1986) described four mentally retarded autistic patients with structural abnormalities involving inversion/duplication of $3 p$ and $16 q ; 5 p+$ and $+7 p-$. More recently, Gillberg and colleagues (1991) described the association of autism in six cases of trisomy 15; they proposed that this may suggest a separate subgroup of autism. In this report, the present authors describe the association of mental retardation and autistic disorder in a girl with an isochromosome $18 \mathrm{q}$ and a second population of cells containing a deletion of the short arm of chromosome 18. To the present authors' knowledge, autism or autistic-like conditions have not been previously described in persons with abnormalities of chromosome 18 .

\section{CASE REPORT}

$\mathrm{JV}$ is a 15-year-old Caucasian girl. She lives with her adoptive parents and attends a special education programme for mentally retarded children. JV was referred with a history of aggressive outbursts and temper tantrums. Behaviours included kicking, screaming, self-biting and aggressive behaviour against other children at school.

Correspondence: M. Ghaziuddin, Division of Child Psychiatry, University of Michigan, Taubman Center - Box 0390, 1500 East Medical Center Drive, Ann Arbor, MI 48109-0390, USA. 
Details about her birth and developmental history are not well documented as she was adopted at the age of 4 years. At the age of 3 years and 9 months, JV was removed from her parental home because of severe physical abuse. After spending some time in a foster home, she was adopted by the present family. JV was in a preschool programme for retarded children at the time of adoption. She continued in this programme for one year, and moved to a school for retarded children at the age of 6 years.

According to the adoptive parents, some of the behaviours which the patient exhibited included: difficulty in following directions; speech abnormalities such as pronoun reversal and monotonous speech, abnormal movements such as rocking for long periods of time and occasional hand-flapping; strong reactions to changes in the environment; spinning and banging of objects; and self-abusive behaviours such as biting.

Medical history revealed several operations for ear problems in JV's childhood. At the time of the present referral, she had a tube in her left middle ear and gave a history of frequent middle ear infections. There was no history of any formal psychiatric illness although JV had been prescribed a variety of psychotropic medications in the past for the control of behavioural problems. She had also been on depo-provera for symptoms suggestive of premenstrual syndrome.

Little information is available of the patient's biological family. Both her biological parents were described in social worker's reports as being mentally retarded although the degree of retardation was not stated. JV has two biological siblings both of whom were adopted out.

Physical examination by the medical geneticist revealed the following findings: microcephaly; round flat facies; flat broad nasal bridge; hypertelorism with slanting palpebral fissures; mild bilateral ptosis with epicanthal folds; slight prognathism; high arched palate with single uvula; down-curved slope of mouth with relative macrostomia; and a thin upper lip with protuberant ears. As shown in Fig. 1, JV was mildly

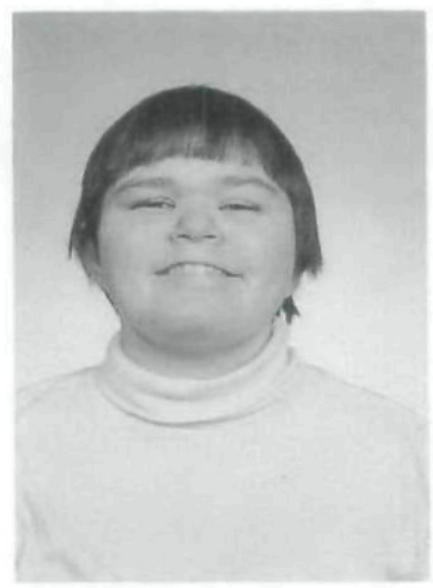

Figure 1. Face of JV at 15 years of age. 

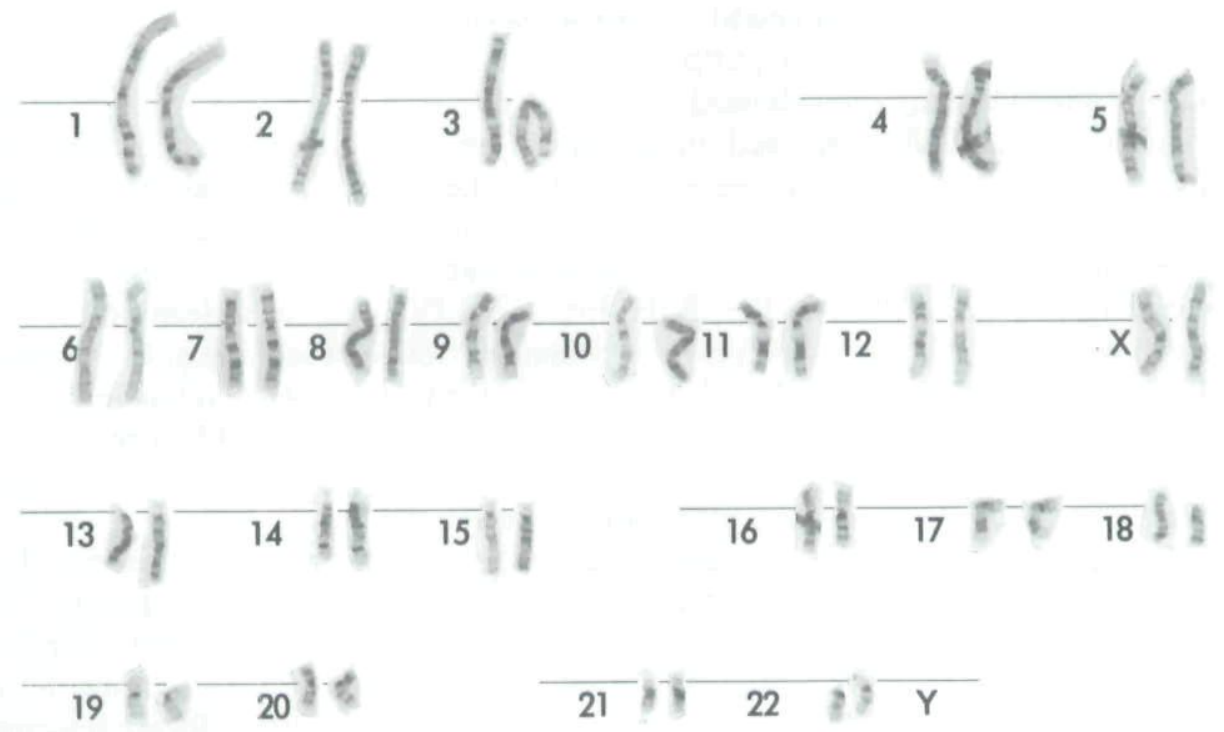

Figure 2. Peripheral blood karyotype of JV: deletion of the short arm of chromosome 18 [del (18) (p11)]. The abnormalities were seen in approximately equal numbers. No normal cells were seen. The abnormal chromosomes 18 are indicated by arrows.
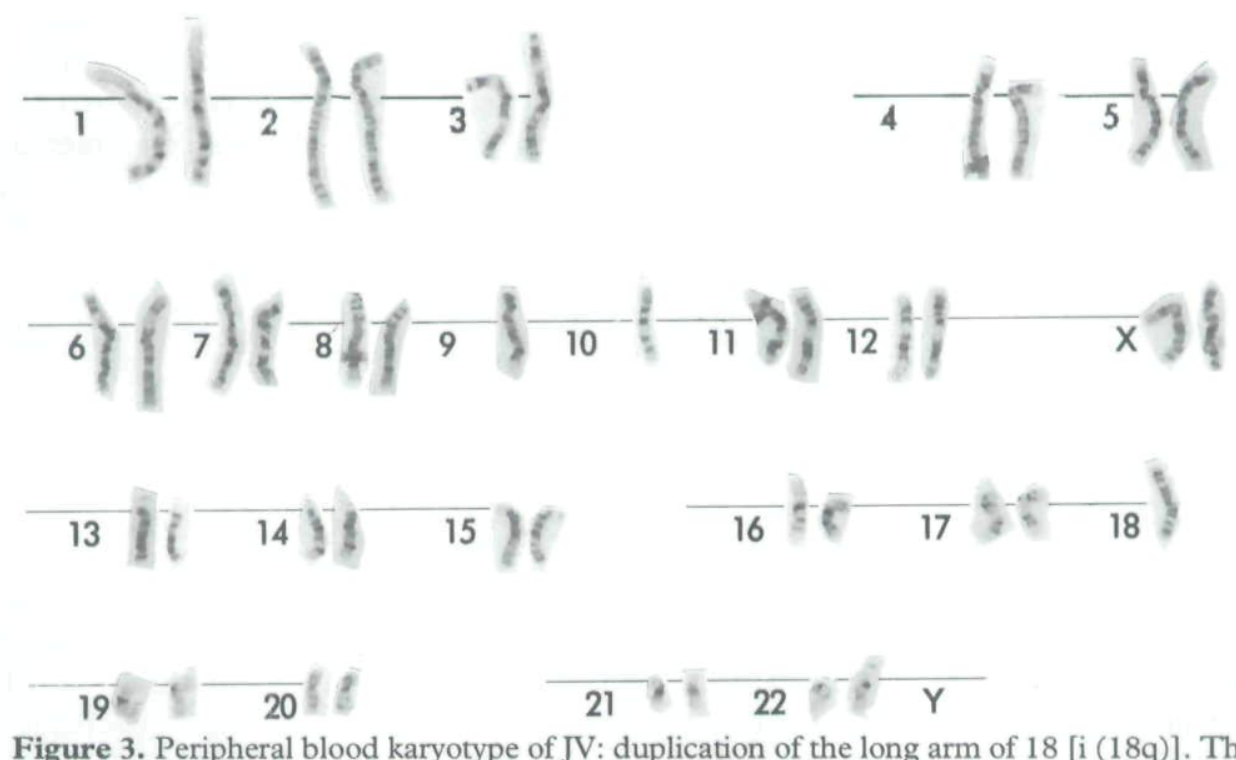

Figure 3. Peripheral blood karyotype of JV: duplication of the long arm of 18 [i (18q)]. The abnormalities were seen in approximately equal numbers. No normal cells were seen. The abnormal chromosomes 18 are indicated by arrows. 
obese with a short neck and excessive nuchal skin. She had mild kyphosis and lardosis. JV's shoulders were broad and her arms short (mesomelia). Her palms and soles were normal. However, her fifth finger was short with slightly increased carrying angles. Genital examination showed small labia minora.

Chromosomal analysis showed mosaicism for abnormalities of chromosome 18, with two cell lines: one with a deletion of 18 p 11.3, i.e. deletion of the short arm (Fig. 2); and another cell line, 44, XX, i (18q) i.e. a duplication of the long arm (Fig. 3).

On mental status examination, JV was alert but not cooperative. She did not appear aggressive or abusive during the interview. JV spoke in a deep voice; her speech was muffled at times with poor articulation. She kept looking at her mother while answering questions. Although JV did not seem to actively avoid looking at the examiners, her eye contact was fluctuant and inconsistent. She could correctly give her age and birth date, and was well oriented in place. Apart from some handflapping and rocking, JV showed no abnormal movements.

Her last full-scale IQ, done 3 years prior to the referral, was reported to be 58 . Her CT scan and EEG were normal. On the Autism Behavior Checklist (Krug et al. 1980), JV was given a score of 87 by her adoptive mother and 101 by her adoptive father, which placed her within the autistic range. On the Child Autism Rating Scale (Schopler et al. 1986), she scored 25, while the cutoff point for autism for adolescents is 28. On the DSM-III-R (APA 1987), JV met the following items on the symptoms checklist for Autistic Disorder: gross impairment in the ability to make peer friendships; abnormal social play as shown by her inability to participate in simple games; abnormal non-verbal communication such as inconsistent eye contact; marked abnormality in the production and form of speech; marked impairment in the ability to initiate and maintain conversation; a restricted range of interests; and stereotyped body movements. Therefore, based on the above findings, JV was diagnosed as suffering from autistic disorder (DSM-II-R, APA 1987) with moderate mental retardation.

\section{DISCUSSION}

JV showed an unusual karyotype: mosaicism for monosomy $18 \mathrm{p}(46, \mathrm{XX}$, del $18 \mathrm{p}$ 11.3) and a functional trisomy for the long arm of chromosome 18 [46, XX, i (18q)]. In addition, she also met the criteria for autistic disorder, as defined by the DSMIII-R (APA 1987), and of moderate mental retardation. Chromosome 18 abnormalities have been described in association with mental retardation and growth delay (Chudley et al. 1974). However, these have not been described in association with a clear diagnosis of autistic disorder. Wilson \& Al Saadi (1989) described a 7-year-old boy with obesity and abnormal behaviour, associated with interstitial deletion of chromosome 18 (q12.2q21.1). The behavioural abnormalities consisted of 'perseveration, patterned movements, easy distractibility, and autistic tendencies'. However, the 'autistic tendencies' were not described and it was not clear if the patient met the criteria for an additional diagnosis of autistic disorder. Patients with deletion of the long arm of chromosome 18 have been described as having a characteristic 
facial dysmorphology with behavioural abnormalities such as aggressive outbursts and hyperactivity (Schinzel 1984).

In another series of seven patients with the typical 18q-phenotype and a common deletion of band 18q21, two patients showed obesity without autistic behaviour (Wilson et al. 1979). JV resembled the patient described by Wilson \& Al Saadi (1989) in showing obesity and behavioural problems, but differed from him in having a clear diagnosis of autistic disorder, in addition to having two abnormal cell lines.

\section{REFERENCES}

American Psychiatric Association (1987) Diagnostic and Statistical Manual of Mental Disorders, 3rd edn, revised. APA, Washington, DC.

Chudley A.E., Bauder F., Ray M., McAlpine P.J., Pena S.D.J. \& Hamerton J. (1974) Familial mental retardation in a family with an inherited chromosome rearrangement. fournal of Medical Genetics 11, 353-63.

Gillberg C., Steffenburg S., Wahlstrom J., Gillberg I.C., Sjostedt A., Martinsson T., Liedgren S. \& Eeg-Olofsson O. (1991) Autism associated with marker chromosome. fournal of the American Academy of Child and Adolescent Psychiatry 30, 489-94.

Krug D.A., Arick J. \& Almond P. (1980) Behaviour checklist for identifying severely handicapped individuals with high levels of autistic behavior. fournal of Child Psychology and Psychiatry 21, 221-9.

Mariner R., Jackson A.W., Levitas A., Hagerman R.J., Braden M., McBogg P.M.. Smith A.C.M. \& Berry R. (1986) Autism, mental retardation and chromosomal abnormalities. fournal of Autism and Developmental Disorders 16, 425-40.

Schinzel A. (1984) Catalogue of Unbalanced Chromosome Aberrations in Man. de Gruyter, Berlin.

Schopler E., Reichler R.J. \& Renner B. (1986) The Child Autism Rating Scale (CARS). Irvington, New York, NY.

Turner B. \& Jennings A.N. (1961) Trisomy for chromosome 22. Lancet i, 49-50.

Wakabayashi S. (1979) A case of infantile autism associated with Down syndrome. fournal of Autism and Developmental Disorders 9, 31-6.

Wilson M.G., Towner J.W., Forsman I. \& Siris E. (1979) Syndromes associated with deletion of the long arm of chromosome 18 [del(18q)]. American fournal of Medical Genetics 3, 155-74.

Wilson G.N. \& Al Saadi A.A. (1989) Obesity and abnormal behavior associated with interstitial deletion of chromosome 18. Fournal of Medical Genetics 26, 62-3. 
This document is a scanned copy of a printed document. No warranty is given about the accuracy of the copy. Users should refer to the original published version of the material. 